\title{
A REVIEW OF LOW BIRTH WEIGHT
}

\author{
Ramachandran U. ${ }^{1}$
}

\section{ABSTRACT:}

As the incidence of low birth weight babies in India and the neighbouring areas is very high a review of the causes of $\mathrm{LBW}$ was done. The factors responsible have been highlighted, risk factors been identified and some remedial measures suggested.

\section{Key Words: LBW - low birth weight, MCH - maternal and child health.}

\section{INTRODUCTION:}

Low Birth Weight (LBW), is a major cause of morbidity and mortality in infants in the developing countries LBW is defined as a birth weight below $2.5 \mathrm{~kg}$ of weight. Earlier the Indian Association of Paediatrics used a definition of a weight below $2 \mathrm{~kg}$ to represent low birth weight because when the 2.5 $\mathrm{kg}$ definition was used, as many as one third of all neonates in South Asia were classified as LBW Nowadays babies with weights below $2 \mathrm{~kg}$ are given special care as many are due to IUGR.

AIM:

The aim of his study was to review the prevalence of LBW in India, Nepal and Sri Lanka and identify the main factors and finally to suggest some actions for reducing the LBW rate.

\section{MATERIALS AND METHODS:}

One major multi-centre study was conducted by the WHO (SEARO), in India, Nepal and Sri Lanka in 1992. ${ }^{1}$ The figures for LBW in that study were as follows:-

\section{Birth Weight Data}

\begin{tabular}{cccc}
\hline Birth Weight & \multicolumn{3}{c}{ Percentage LBW \% } \\
(Mean) & Nepal & India & Sri Lanka \\
\hline$<2.0 \mathrm{~kg}$ & 1.5 & 4.5 & 2.5 \\
$2-2.25 \mathrm{~kg}$ & 7.3 & 9.7 & 5.0 \\
\hline $2.25-2.5 \mathrm{~kg}$ & 5.6 & 13.9 & 10.9
\end{tabular}

These dismaying figures are further compounded by the observation that the cause of LBW is more often Intra Uterine Growth Retardation (IUGR), rather than premature deliveries.

1. Dept. of Paedeatics, Manipal College of Medical Sciences, Pokhara, Nepal.

Address for correspondence : Dr. U. Ramachandran, Dept. of Paedeatics

Manipal College of Medical Sciences, Pokhara, Nepal. 
CATEGORIES OF LBW:

LBW infants are broadly classified under two major categories.

a) Neonates who are born Small for Gestational Age (SGA) as a result of factors affecting the rate of Intrauterine Growth and

b) Neonates whose birth weight is appropriate for their gestational age (AGA), but who are born prematurely, due to factors affecting the duration of gestation.

\section{ETIOLOGICAL FACTORS:}

The etiological factors for both categories overlap and are described below

\section{SOCIOECONOMIC FACTORS:}

\section{POVERTY:}

Poverty is the most important issue to be considered and underscores the following causes which to a large extent arise from poverty. UNDP has developed a measure of poverty called the HPI (Human Poverty Index) This index concentrates on three essential elements of human life.

a) Longevity - The percentage of people expected to die before 40 years of age.

b) Knowledge - Percentage of Adults who are illiterate.

c) A Decent standard of Living -

- Percentage of people with access to safe water and health.

- Percentage of malnourished children below five years.

The HPI provides a strong reminder that eradicating poverty always requires more than just increasing the income of the poorest people. ${ }^{2}$

In India the HPI ranges from a low of $15 \%$ in Kerala to over $50 \%$ in Bihar and Rajasthan with a National average that leaves little to be proud about $35.9 \%$ and which gives India a rank of 47 amongst 77 developing countries.

\section{MATERNAL RISK FACTORS:}

\section{A) Maternal Age and Weight:}

Maternal ages below eighteen years and above thirty five years are associated with higher rates of $\mathrm{LBW}$.

Low maternal weight also influences the weight of the baby. However if the weight gain during pregnancy is good then the outcome of the neonate's weight will reflect that the mother had adequate nutrition during pregnancy.

\section{B) Maternal Malnutrition:}

Maternal malnutrition is the most important correlate for LBW in developing countries. Maternal malnutrition is caused by poverty as well as by the gender bias in food distribution within the family.

\section{C) Maternal Stress:}

There are many factors which produce stressful situations in the pregnant woman. e.g. strenuous physical activity throughout pregnancy such as sweeping, swabbing, washing clothes, fetching water within the house and others like domestic service, carpet making, farming etc.

The energy loss is not compensated by adequate calorie intake. Upright posture during working may diminish uterine blood supply thus affecting the supply of oxygen and nutrients to the foetus. Mental stress within and outside the home are compounded by a bad working environment with exposure to smoke.

\section{D) Short Birth Intervals:}

Short birth intervals of less than two years. 


\section{E) General maternal illnesses:}

General maternal illness like anemia, tuberculosis, and malaria are prevalent and take a toll of the lives and health of both mother and baby.

\section{F) Gender Bias:}

Gender bias focuses on the inequalities between the two sexes. This discrimination begins in utero. Selective abortion of female foetuses has been reported. It was seen that of 8000 foetuses only one was male. Girls received less food than boys even if they did more work. This disparity can lead to significant retardation of growth and development from early childhood. Hence many girls enter the reproductive age with malnutrition and anaemia. This is turn will affect the health of the baby. ${ }^{3}$

\section{G) Education:}

Female literacy has increased in many countries but still remains a big problem. Both maternal and paternal education have a direct affect on the birth weight of LBW babies. This is because with education the general awareness improves and antenatal care is availed of. Educating girls means educating the nation.

\section{H) Consanguinity:}

Consanguinity, a known risk factor for genetic disorders was present in $13 \%$ of marriages, which would be a low figure for other parts of the country where consanguinous marriages are even more prevalent.

\section{I) Alcohol and Tobacco Consumption:}

Alcohol and Tobacco consumption during pregnancy are important contributory factors at both ends of the social spectrum.

\section{J) Antenatal Care:}

Access to proper antenatal care and to treatment of pregnancy related problems like Pregnancy
Induced Hypertension. Bleeding during pregnancy multiple pregnancies and so on are not easily available.

\section{K) Past History of Premature Births:}

This is associated 3-4 times increased risk of premature births.

\section{PHYSIOLOGICAL PROBLEMS OF LBW ${ }^{4}$}

\section{1) Respiratory -}

a) RDS due to surfactant deficiency.

b) Apnoea due to immaturity of breathing mechanism.

c) Prematurity with bronchopulmonary dysplasia and chronic

Pulmonary insufficiency

\section{2) Neurological -}
a) Intracranial haemorrhage
b) Hypoxic Ischaemic Encephalopathy

3) CVS -
a) Hypotension
b) Persisting PDA leading to $\mathrm{CCF}$

4) Haematological -
a) Anaemia
b) Hyperbilirubinaemia

5) GIT -
a) Necrotizing enterocolitis
b) Delayed colonization of the gut
c) Immaturity of hepatic enzymes

6) Metabolic -

Hypocalcaemia and hypoglycaemia

7) Temperature regulation -

Hypo and hyperthermia due to immaturity of temperature regulatory mechanism

8) Immunity -

Greater risk of infections due to poorly developed immune system

\section{COMPLICATIONS:}

Low birth is the most significant indicator of the 
chance of survival of a baby and its health and development. The main complications that may arise are

- Low birth babies are at a higher risk of death and severe morbidity not only during the neonatal period but also during infancy and childhood.

- They have 3-4 times greater risk of dying from diarrhoeal diseases and acute respiratory infections.

- They are more likely to be malnourished and hence to be stunted.

- There is mounting evidence that there may be a link between LBW and cardiovascular disease, hypertension and diabetes in adult life.

\section{PREVENTION:}

The important strategies for safe motherhood have clearly been outlined in "Safe Motherhood".

The various strategies referred to above also encompass the approaches taken up for intervention as part of various $\mathrm{MCH}$ programmes and include.

a) The health of both women and children can be significantly improved by spacing births at least two years apart,

b) By avoiding pregnancies before the age of 18 or after 35 ,

c) By limiting the total number of pregnancies to four,

d) Family planning gives couples this choice,

e) To reduce the dangers of childbearing all pregnant women should go to a health worker for prenatal care.

f) All births should be assisted by a trained person.

g) All families should know the warning signs.

h) Girls who are healthy and well fed during their own childhood and teenage years have fewer problems in pregnancy and childbirth. i) All women need more food during pregnancy as well as more rest.

WARNING SIGNS FOR PREDICTING LBW: Before pregnancy begins:

- Interval of $<2 \mathrm{yr}$ since last birth.

- Mothers age $<18$ or $>35$ yr.

- $>4$ previous children.

- Previous history of LBW bay.

- Previous history of difficult delivery / LSCS.

- Previous history of miscarriage, abortion, stillbirth.

- Maternal weight $<35 \mathrm{~kg}$ before pregnancy.

- Height $<145 \mathrm{~cm}$.

\section{During Pregnancy:}

- Weight gain $<6 \mathrm{~kg}$ during pregnancy.

- Pallor.

- Swelling of face or feet.

\section{Immediate help required:}

- Bleeding PV during any stage of pregnancy.

- Severe headache [sign of hypertension].

- Severe vomiting.

- High Fever.

\section{THE PYRAMID:}

Using the diagrammatic representation of a pyramid, the author wishes to depict levels of care, required at various stages in order to constitute a preventive approach to $\mathrm{LBW}$.

The base of the pyramid describes the need for long term investment in the health and education of the girl child to guarantee the reproductive health of future mothers. The apex of the pyramid stresses the need for access to good medical care during pregnancy to prevent the onset of early labour and to prevent complications. 


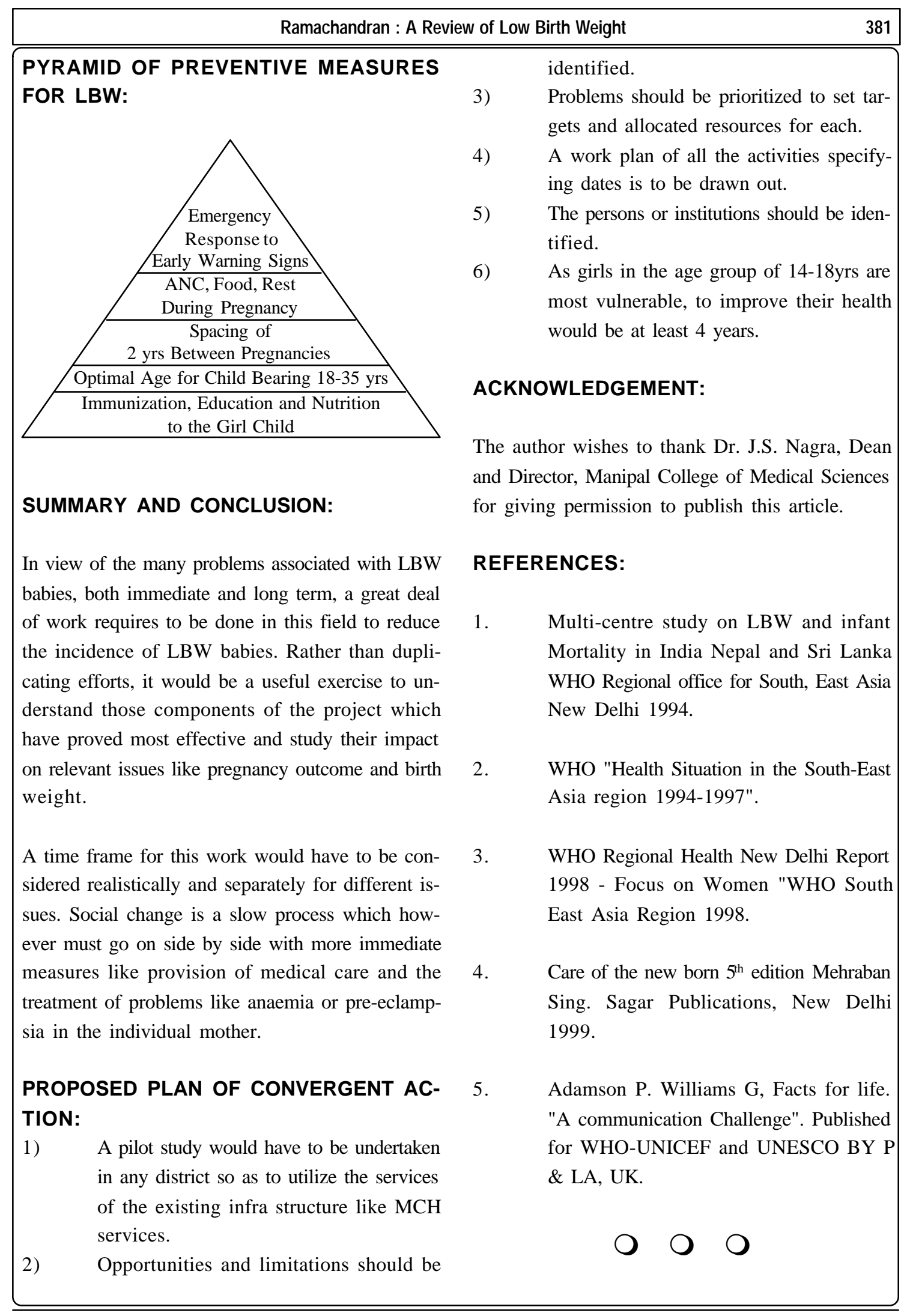

